\title{
Multiobjective Optimization regarding Vehicles and Power Grids
}

\author{
Kaiyang Zhong $\mathbb{D},{ }^{1}$ Ping Wang, ${ }^{1}$ Jiaming Pei $\mathbb{D},{ }^{2}$ Jiyuan $X u\left(\mathbb{D},{ }^{2}\right.$ Zonglin Han $\mathbb{D},{ }^{3}$ \\ and Jiawen $\mathrm{Xu}$ iD ${ }^{4}$ \\ ${ }^{1}$ School of Economic Information Engineering, Southwestern University of Finance and Economics, Chengdu, Sichuan, China \\ ${ }^{2}$ School of Computer Science and technology, Taizhou University, Jiangsu, China \\ ${ }^{3}$ Zhengzhou Electric Power Vocational and Technical College, Zhenzhou, China \\ ${ }^{4}$ College of Artificial Intelligence, Tianjin University of Science and Technology, Tianjin, China
}

Correspondence should be addressed to Jiaming Pei; jiamingpei0262@gmail.com

Received 11 April 2021; Accepted 2 June 2021; Published 14 June 2021

Academic Editor: Yuanpeng Zhang

Copyright $\odot 2021$ Kaiyang Zhong et al. This is an open access article distributed under the Creative Commons Attribution License, which permits unrestricted use, distribution, and reproduction in any medium, provided the original work is properly cited.

\begin{abstract}
Vehicle to Grid (V2G) refers to the optimal management of the charging and discharging behavior of electric vehicles through reasonable strategies and advanced communication. In the process of interaction, there are three stakeholders: the power grid, operators (charging stations), and EV users. In real life, the impact of peak-valley difference caused a lot of power loss when charging. At the same time, the loss of current is also a loss for power grid companies and EV users. In this paper, we propose a multiobjective optimization method to reduce the current loss and determine the relationship between the parameters and the objective function and constraints. This optimization method uses a genetic algorithm for multiobjective optimization. Through the analysis of the number of vehicles and load curve of AC class I and AC class II electric vehicles before and after optimization in each period, we found that the charging load of electric vehicles played a role of valley filling in the low valley price stage and played a peak-cutting role in a peak price period.
\end{abstract}

\section{Introduction}

Automobile energy consumption accounts for nearly a quarter of the world's total energy consumption. With the improvement of the economic level of developing countries [1], the number of automobiles is increasing sharply, and the energy and environmental problems caused are becoming more serious [2]. Governments around the world are actively promoting electric vehicles. In addition to a series of economic subsidy policies regarding production and sales, many countries, including China, have also proposed the agenda the formulation of a timetable to ban the sale of fuel-fired vehicles. Electric vehicles (EVS) are considered a solution to reduce air pollution and greenhouse gas emissions. As a result, their market share has increased exponentially in recent years [3]. The energy of electric vehicles mainly comes from the power grid, which brings challenges to the distribution network, such as the increase of the peak-valley load difference, voltage drop, and loss increase. However, electric vehicles have broad appli- cation prospects in peak shaving, valley filling, power system auxiliary services, and the coordinated absorption of new energy as a mobile energy storage [4]. The main tasks are allocating, setting up charging stations, and regulating the timing of the photovoltaic power generation and power supply, which can minimize user costs and the loss of the power grid.

Many scholars have proposed solutions to the problem of electric vehicles from different angles. Miao et al. [5] introduced and compared the key components of lithium-ion batteries and described the related battery management system and the methods for improving the overall battery efficiency, capacity, and life. Researchers [6, 7] studied the energy management strategies and charging technology for pure electric vehicles, discussed the main challenges and corresponding solutions faced by pure electric vehicles, and introduced the latest developments in pure electric vehicles.

However, research and political interest in public charging has increasingly focused on fast charging options and high electricity prices, but few estimates of future demand. 
Gnann et al. [8] contributed to the research field related to policy by determining the number of fast charging stations required for each electric vehicle in the queuing model and the potential additional electricity saved per kilowatt hour. Furthermore, Pei used the PSO of intelligent computing to solve the charging and discharging theory of electric vehicles earlier [9], which provided inspiration.

In this paper, our main contribution is to propose a multiobjective optimization method to reduce the current loss of electric vehicles during the charging process, which is of benefit to both electric power companies and electric vehicle owners. The work we have done is as follows:

(1) Select the Monday charging record to arrange. As the charging connection time is the physical connection time between the electric vehicle and the charging pile, the charging power is divided by the charging connection time, and the maximum power in a week is regarded as the minimum power of the car, which is sorted by power from small to large

(2) With the goal of minimizing user charging costs, the optimal allocation plan for 5000 vehicles in a 24-hour period is obtained. In addition to the power limit of the line, the vehicle's own charging and discharging power limit, the battery SOC limit, etc. are constraints, and the final power of each vehicle is $50 \mathrm{kWh}$

\section{Problem Description}

A new energy charging station provides charging service for electric vehicles by utilizing grid energy and new energy in the station and can send the new energy in the station back to the grid. Figure 1 shows the system structure of a new energy charging station. There are eight charging piles and photovoltaic power generation devices in the station. The charging power of each charging pile can be adjusted in the range of $50 \mathrm{~kW}$ [10]. Some symbol descriptions are shown in Table 1.

When electric vehicles are parked in residential areas, this often exchanges electricity directly with the distribution network through charging piles (i.e., charging or discharging), which may lead to a significant change in the distribution of power flow.

Figure 2 shows the distribution network topology of a residential area.

Assuming that node 8 is connected to 100 electric vehicles, $10 \%$ of them are charged by AC level 1 and $90 \%$ are charged by AC level 2. The discharge power is not more than $5 \mathrm{~kW}$. The battery capacity of the electric vehicle is $50 \mathrm{kWh}$, and the state of charge (SOC) of the battery is no less than 0.2 [11].

We must provide the optimal charging and discharging scheme to minimize the active power loss for the power grid and the total cost of electric vehicle owners by establishing an optimization model under the circumstance where the optimal period is 24 hours a day.

\section{Methods and Experiments}

3.1. Classification Model of Electric Vehicle Charging Power Level. Given the charging power meter of 100 electric vehicles

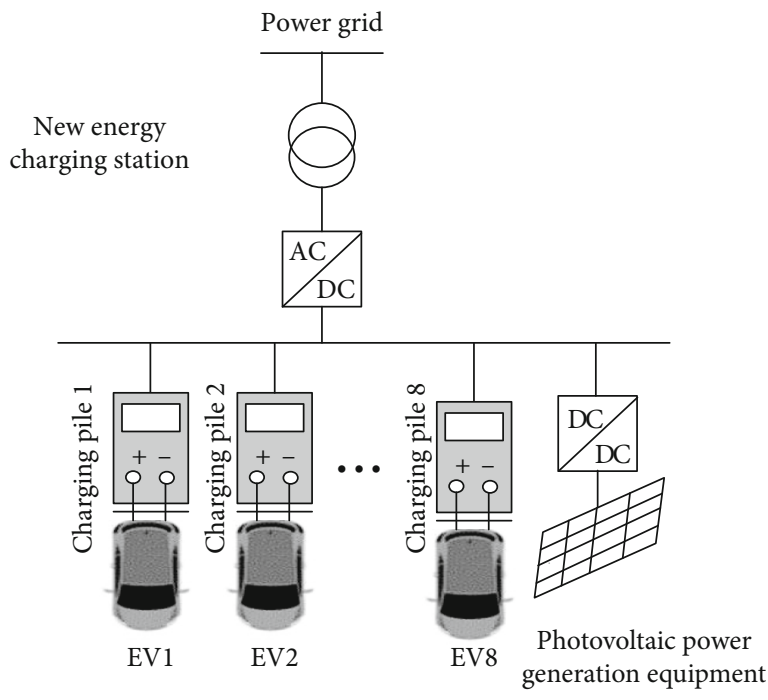

FIGURE 1: New energy charging station structure.

in a city, we can calculate the minimum power of electric vehicles in a day. The function is as follows:

$$
P_{\min }=\frac{w}{t_{\max }}
$$

We used an Excel function to process the data and used the automatic sorting function in Excel to ascend the minimum charging power and classify the top 10 vehicles into AC class 1 (1.4-1.9 kW). We, thus, obtained Table 2.

3.2. Drawing the 24-Hour Charging Load Curve. To more accurately calculate the actual charging time of electric vehicles according to the data of Table 2 , the average value of the power interval is

$$
P_{i}=\frac{P_{i 1}+P_{i 2}}{2}
$$

After substituting the data in Table 1, we can obtain the charging power of $\mathrm{AC} 1$ at $P_{1}=1.65 \mathrm{~kW}$, the power of $\mathrm{AC}$ 2 is $p_{2}=33.3 \mathrm{~kW}$, and DC power is $p_{3}=70 \mathrm{~kW}$.

According to the energy formula, the actual charging time for each charging power class of electric vehicle is calculated, the actual charging time of $\mathrm{AC} 1$ is

$$
t_{r}=\frac{w}{P_{1}}
$$

The time of $\mathrm{AC} 2$ is

$$
t_{r}=\frac{w}{P_{2}}
$$

The time of DC is

$$
t_{r}=\frac{w}{P_{3}} .
$$


TABLE 1: Symbol descriptions.

\begin{tabular}{lr}
\hline Symbol & Significance \\
\hline$\Delta A$ & Power loss or power consumption in the circuit \\
$I$ & Load current through the circuit \\
$R$ & The resistance value of the wires that make up the circuit \\
$t$ & The elapsed time for the circuit to be powered \\
$U$ & Voltage \\
\hline
\end{tabular}

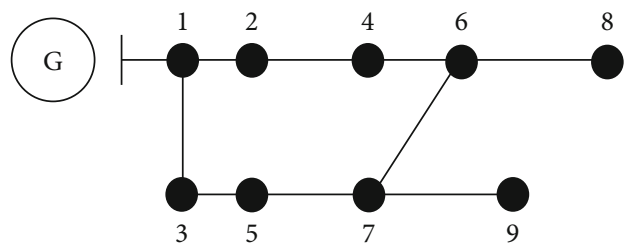

Figure 2: Distribution topology picture of a residential area.

TABle 2: Minimum charging power ascending arrangement of 100 electric vehicles on Monday.

\begin{tabular}{|c|c|c|c|c|}
\hline $\mathrm{S} / \mathrm{N}$ & $\begin{array}{l}\text { Charging } \\
\text { time }(\mathrm{h})\end{array}$ & $\begin{array}{c}\text { Monday } \\
\text { Charging } \\
\text { capacity (kWh) }\end{array}$ & $\begin{array}{c}\text { Minimum } \\
\text { power }(\mathrm{kW})\end{array}$ & Classification \\
\hline 79 & 39.76 & 1.25 & 0.314 & \multirow{7}{*}{ AC $110 \%$} \\
\hline 72 & 24.66 & 11.04 & 0.448 & \\
\hline$\cdots$ & $\ldots$ & $\ldots$ & $\ldots$ & \\
\hline 8 & 1.29 & 0.94 & 0.729 & \\
\hline 39 & 10.09 & 7.64 & 0.758 & \\
\hline 76 & 28.27 & 21.80 & 0.771 & \\
\hline 42 & 0.83 & 0.68 & 0.819 & \\
\hline 98 & 15.50 & 13.44 & 0.867 & \multirow{7}{*}{ AC $240 \%$} \\
\hline 44 & 9.17 & 8.07 & 0.880 & \\
\hline$\cdots$ & $\cdots$ &.. & $\cdots$ & \\
\hline 36 & 1.47 & 2.45 & 1.667 & \\
\hline 88 & 16.36 & 27.6 & 1.687 & \\
\hline 23 & 10.18 & 17.31 & 1.700 & \\
\hline 63 & 9.24 & 15.95 & 1.726 & \\
\hline 66 & 13.62 & 24.36 & 1.789 & \multirow{11}{*}{ DC $50 \%$} \\
\hline 91 & 9.83 & 17.72 & 1.802 & \\
\hline 12 & 6.88 & 12.5 & 1.817 & \\
\hline 51 & 3.15 & 5.83 & 1.851 & \\
\hline 37 & 7.9 & 14.83 & 1.877 & \\
\hline$\ldots$ & $\ldots$ &.. & $\ldots$ & \\
\hline 9 & 4.61 & 22.79 & 4.941 & \\
\hline 16 & 3.08 & 15.95 & 5.179 & \\
\hline 53 & 2.91 & 16.26 & 5.588 & \\
\hline 11 & 1.61 & 9.96 & 6.186 & \\
\hline 34 & 0.37 & 12.72 & 34.378 & \\
\hline
\end{tabular}

Then, we can calculate that actual charging end time is

$$
t_{e}=t_{s}+t_{r}
$$

Thus, the actual charging start-stop time of the electric vehicles is in $\left[t_{s}, t_{r}\right]$.

If we divide a 24-hour and 15-minute period into 96 time periods and use the cyclic algorithm to distribute the starting and stopping charging time data of 100 vehicles into 96 intervals, each interval is calculated by summing up the charging power of the corresponding AC-grade electric vehicles, and the charging power of 100 vehicles in 24 hours is obtained. By using MATLAB to plot the charging power of 100 vehicles in 24 hours, the charging load curve is plotted by function and the result is shown in Figure 3.

According to the difference between the highest power point and the lowest power point in the figure, the peakvalley difference of the charging load of 100 vehicles in 24 hours is $4200 \mathrm{kWh}$ when the proportion of electric vehicles charged by AC 1 is $10 \%$, charged by AC 2 is $40 \%$, and charged by $\mathrm{DC}$ is $50 \%$.

3.3. Optimizing the Ratio of the Charging Power Level. For 100 electric vehicles, the proportion of "AC 1," "AC 2," and "DC charging" electric vehicles after optimization is set to be $x, y$, and $z$, respectively, to redistribute their charging power levels and adjust their actual charging time to achieve the goal of modernization. To reduce the equipment investment and reduce the peak-valley difference, we used the actual charging time and cycle algorithm to distribute time and accumulate power. The weight of the equipment investment and the peak-valley difference is $1: 1$, and the objective function is as follows:

$$
A_{\text {min }}=Y_{\text {min }}+\Delta p
$$

In the process of optimizing the proportion of charging vehicles of different grades, we obtain the minimum objective function $A_{\min }$ when the proportion of "AC 1," "AC 2," and "DC charging" electric vehicles is 46:53:1. Therefore, the minimum investment in equipment is

$$
Y_{\min }=140900000
$$

The minimum peak-valley difference is

$$
\Delta p=W_{\max }-W_{\min }=18810 \mathrm{~kW} .
$$

Using MATLAB, the charging load curve of 10,000 electric vehicles in 24 hours after optimization is drawn as shown in Figure 4. Compared with Figure 3, it is clear that the optimized peak value diminishes in magnitude and the peakvalley difference decreases significantly.

\section{Optimizing Method}

4.1. Establishment of Model. Based on the above analysis and calculation, we can obtain the total power consumption, which is shown as formulation (11). 


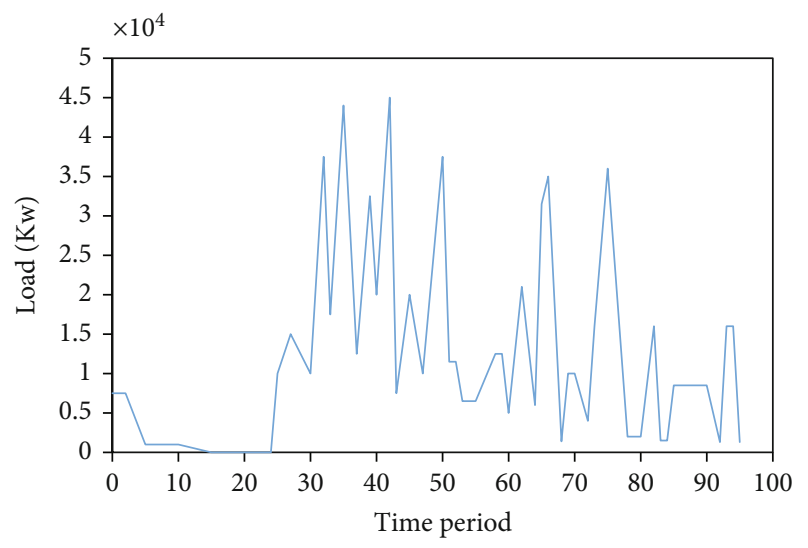

FIgURE 3: The charging load curve of 100 charged vehicles in 24 hours.

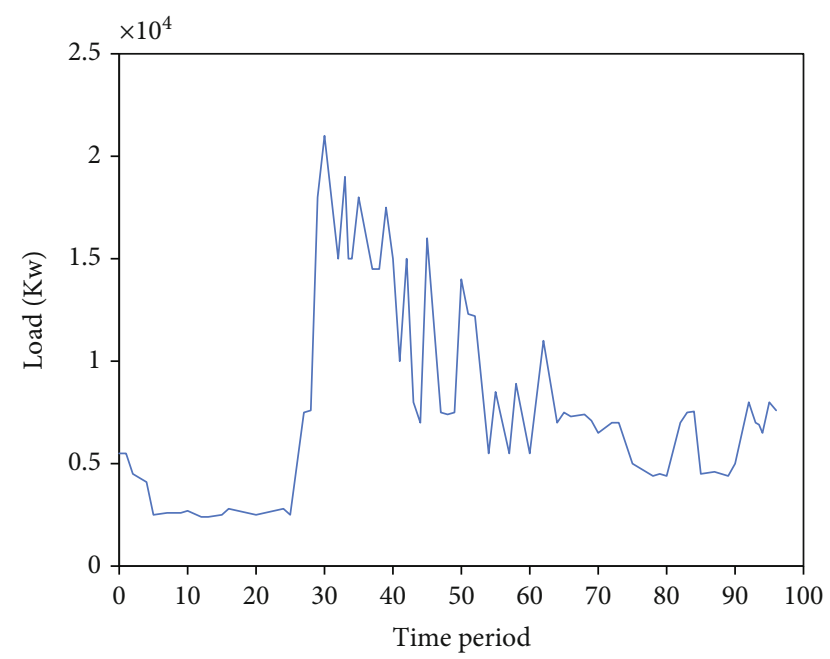

FIgURE 4: The charging load curve of 10,000 electric vehicles 24 hours after optimization.

The parallel parts of $I$ and $U$ produces Joule heat and active power loss, while the orthogonal part is the conversion of the electric field and magnetic field, which does not produce active power loss. When $T=i$, the voltage values of the nine nodes are $U_{j i}, i=1,2,3, \cdots, 9$, respectively. When $T=i$, the number of two types of electric vehicles charged by charging piles is $N_{1 i}, N_{2 i}$, the number of two types of vehicles discharged by charging piles is $N_{3 i}, N_{4 i}$, the charge price is the CPI, and the selling price is the EPI.

The charging behavior optimization model of electric vehicles in a distribution network:

$$
\begin{gathered}
\min \quad W_{\text {extra }}(N) \\
\min \quad S(N) \\
\text { s.t. }\left\{\begin{array}{l}
U_{i} \geq 0.95(i=1,2,3, \cdots, 9) \\
\frac{W_{1}}{\Delta t_{3}}<5, \frac{W_{1}}{\Delta t_{4}}<5 \\
\sum_{i=1}^{24} \sum_{j=1}^{4} N_{j, i}=5000 \\
P_{c, j}(t)<5, P_{c, j}(t)<5 .
\end{array}\right.
\end{gathered}
$$

Among them, $i$ is the starting time of charging and discharging, $j$ represents the AC 1 of electric vehicles, and $j^{\prime}$ represents the AC 2 of that. $P_{c j},(t)$ and $P_{c j^{\prime}}(t)$, respectively, indicate the charging power and discharging power of vehicle NO.J at time $i$.

$$
\begin{aligned}
\Delta P & =\frac{R * 10^{-3}}{U_{b}^{2} \cos ^{2} \varphi} p^{2}, R=0.16 \times \frac{U_{b}^{2}}{p_{B}}=25.644 \Omega, I=Y V, Y \\
& =G+B, V=Z I, Z=R+j X .
\end{aligned}
$$

4.2. The Solution of Optimal Algorithms. Taking $N_{j, i}$ as the optimization variable and making use of the genetic algorithm for multiobjective programming, we obtained the optimal peak and valley cost of the charging and discharging number about AC class 1 and AC class 2 in each period and the load curve of the power grid before and after optimization. The flow chart of the algorithm is shown in Figure 5.

The steps for solving the optimization algorithm are as follows:

(Step 1) Initialize the load parameters and electric vehicle parameters of each node in the power grid, including the load value of the power grid, battery capacity, charging and discharging power, charging state, average energy consumption, and other parameters at each time of day

(Step 2) Randomly generate peak and valley initial populations at each level and time, and then generate 200 initial populations within the range of devalues

(Step 3) Compute the constraints of population, including equality constraints and inequality constraints. Populations that do not satisfy the constraints are discarded directly. The initial population that satisfies the constraints of the optimization model is obtained, and the discharge power and the number of EVs at all stages of charging and discharging are calculated

(Step 4) Produce a progeny population by crossing and mutating in the survived individuals, under the circumstance where the crossover probability is $P_{c}=0.8$ and the mutation variable is $P_{m}=0.2$ [12]

(Step 5) Optimize iteratively until the maximum genetic algebra equations have been reached, and calculate the discharge power of the electric vehicle and the number of electric vehicles at all stages of charging and discharging

4.3. Example Analysis. Taking Chengdu as an example, the parameters of electric vehicles are as follows in Table 3.

Under the guidance of changing electricity prices, some owners responded to the peak-valley price, charged and 


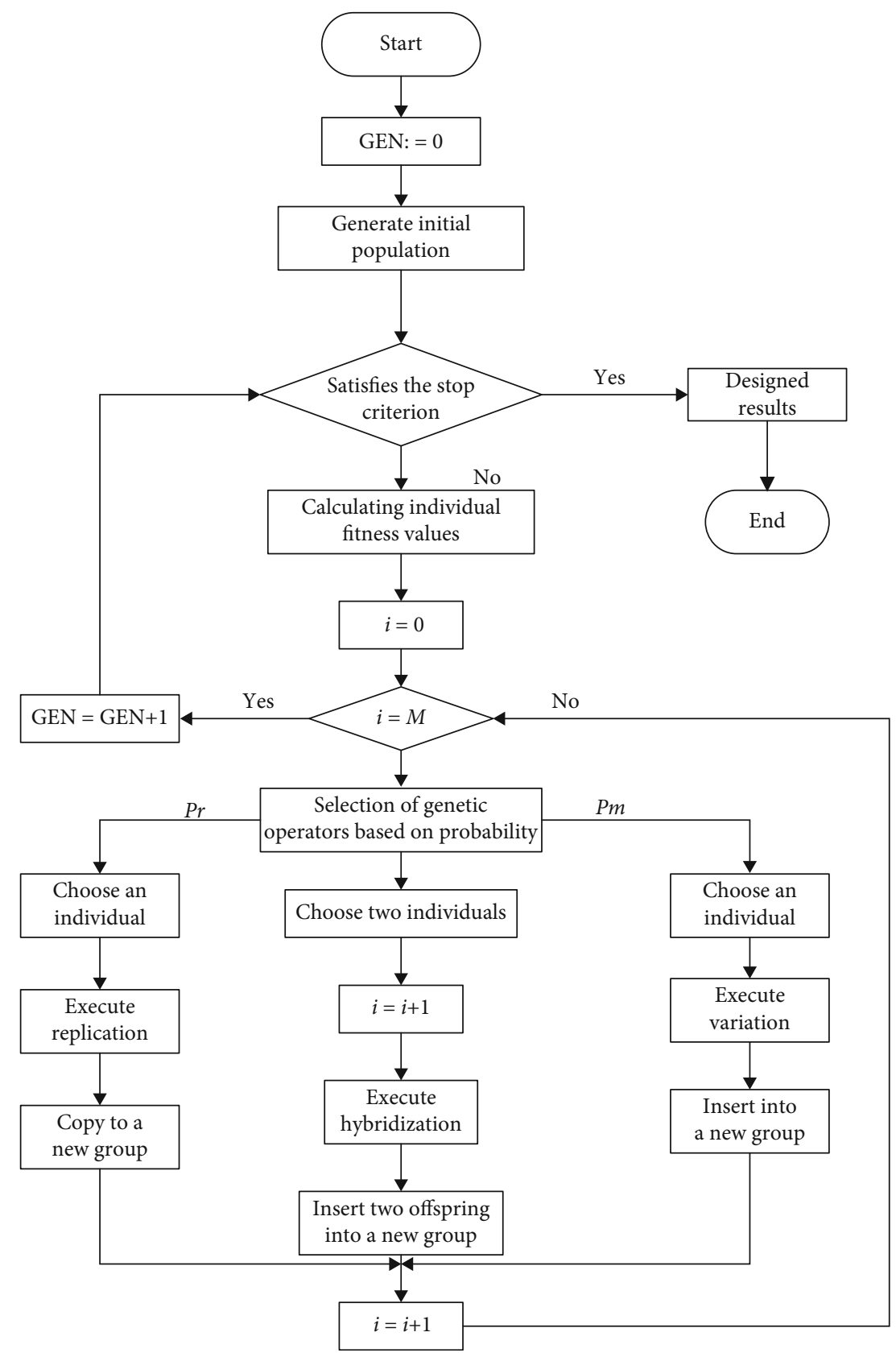

FIGURE 5: Optimal flow chart.

TABle 3: Results.

Battery capacity Energy consumption Start date Charged state

\begin{tabular}{llll}
\hline $50 \mathrm{kWh}$ & $0.15 \mathrm{~J}$ & 3.5 & $20 \%-90 \%$ \\
\hline
\end{tabular}

TABLE 4: Comparison of results before and after optimization.

\begin{tabular}{lc}
\hline Comparison & Peak load \\
\hline Before optimization & $2.7395 \mathrm{kWh}$ \\
After optimization & $2.587 \mathrm{kWh}$ \\
Reducing peak load after optimization & $0.0424 \mathrm{kWh}$ \\
\hline
\end{tabular}

discharged according to the peak-valley price period, combined with the charging and discharging time. Finally, we found that orderly charging and discharging of electric vehicles indeed reduced the peak-valley difference and active power loss of the power grid. Based on the charging load curve of the Chengdu electric vehicles, the results before and after the peak-valley period optimization can be obtained. The results are shown in Table 4.

Thus, in the valley price stage, the charging load of EV had a valley filling effect, and in the peak price period, the discharge load of EV played a peak cutting role. Optimizing distribution networks can effectively reduce the peak-valley differences and achieve cost-saving goals. 


\section{Conclusion}

New energy vehicles have far-reaching social significance regarding sustainable development, alleviating the energy crisis, improving the utilization rate for new energy, and helping the environment. The development path of the new energy automobile industry supported by the government policy is broad, and the future market application prospects are immeasurable. Realizing the scale and industrialization of new energy vehicles requires the improvement of core technology and product performance as well as regarding consumers' awareness of environmental protection [13]. However, there are also many problems in the interactions between electric vehicles and power grids.

The construction of new energy charging stations is expensive, and the disorderly charging of electric vehicles further increases the peak-valley gap of the power grid [14]. Therefore, it is necessary to establish a reasonable proportion model of electric vehicle charging power level, reduce the equipment investment for new energy charging stations, reduce the peak-valley difference of power grids, and reduce the power system consumption.

\section{Data Availability}

To be frank, I derived the writing material from different journals as provided in the references. A MATLAB tool has been utilized to simulate our concept.

\section{Conflicts of Interest}

The authors declare that they have no conflicts of interest.

\section{Authors' Contributions}

Kaiyang Zhong is assigned to the conceptualization, methodology, software, validation, writing, editing, reviewing, and funding. Ping Wang is responsible formal analysis, investigation, and supervision. Jiaming Pei is responsible for the data curation, writing, editing, reviewing, and methodology. Jiyuan $\mathrm{Xu}$ did the conceptualization and investigation. Jiawen $\mathrm{Xu}$ participated in writing, editing, reviewing, and supervision.

\section{References}

[1] R. Wrobel and B. A. Mecrow, "Comprehensive review of additive manufacturing in construction of electrical machines," IEEE Transactions on Energy, vol. 35, no. 2, pp. 1054-1064, 2020.

[2] G. A. Yue-fanga, L. I. Yong-shenga, L. U. Xinb, and R. E. Xianyib, "Optimization control technique for wastewater treatment based on particle swarm algorithm," Application Research of Computers, vol. 28, no. 9, pp. 3318-3320, 2011.

[3] Y. Xu, Y. Zheng, and Y. J. A. E. Yang, "On the movement simulations of electric vehicles: a behavioral model-based approach," Applied Energy, vol. 283, article 116356, 2021.

[4] Y. Gao and S.-l. Xie, "Chaotic particle swarm optimization algorithm," Computer Science, vol. 31, no. 8, pp. 13-15, 2004.
[5] Y. Miao, P. Hynan, A. von Jouanne, and A. J. E. Yokochi, "Current Li-ion battery technologies in electric vehicles and opportunities for advancements," Energies, vol. 12, no. 6, p. 1074, 2019.

[6] Z. Li, A. Khajepour, and J. J. E. Song, "A comprehensive review of the key technologies for pure electric vehicles," Energy, vol. 182, pp. 824-839, 2019.

[7] M. R. Khalid, M. S. Alam, A. Sarwar, and M. S. Jamil Asghar, "A Comprehensive review on electric vehicles charging infrastructures and their impacts on power-quality of the utility grid," ETransportation, vol. 1, article 100006, 2019.

[8] T. Gnann, S. Funke, N. Jakobsson, P. Plötz, F. Sprei, and A. Bennehag, "Fast charging infrastructure for electric vehicles: today's situation and future needs," Transportation Research Part D: Transport and Environment, vol. 62, pp. 314-329, 2018.

[9] J. Pei, "Solving the problem of Charging and Discharging of Electric Vehicles based on Particle Swarm Algorithm," Book Solving the problem of Charging and Discharging of Electric Vehicles based on Particle Swarm Algorithm, pp. 534-538, 2019.

[10] A. Yan-ping, "Research on Intelligent Management System of New Energy Charging Makeup," Book Research on Intelligent Management System of New Energy Charging Makeup, 2016.

[11] M. Shepero, J. Munkhammar, J. Widén, J. D. K. Bishop, and T. Boström, "Modeling of photovoltaic power generation and electric vehicles charging on city-scale: a review," Renewable and Sustainable Energy Reviews, vol. 89, pp. 61-71, 2018.

[12] L. Kai-kai, "Overview of SOC research on pure electric vehicle power battery," Internal combustion engine and accessories, vol. 13, pp. 23-24, 2019.

[13] T. Yue, L. Cong, H. Chang-Qiang, and Y. Wang, "Formation selection and optimization of multiple UAVs," Computer simulation, vol. 36, no. 5, pp. 98-104, 2019.

[14] J. Perez-Vaquero, J. Landauer, H. Briesen, and P. Foerst, “A particle tracking velocimetry method to measure size and charge distributions in tribocharged powder particles," Chemical Engineering Science, vol. 229, article 116036, 2021. 